\title{
Acomparative leakage study on Er,Cr:YSGG laser- and bur- prepared Class $V$ cavities restored with a low-shrinkage composite using different filling techniques
}

\author{
Fernanda Strohmayer Sarabia1, Andréa Dias Neves Lago², Sérgio Brossi Botta³, Cynthia Soares de Azevedo', \\ Narciso Garone-Netto', Adriana Bona Matos ${ }^{1}$
}

'Department of Operative Dentistry, School of Dentistry, University of São Paulo (USP), São Paulo, SP, Brazil 2Department of Operative Dentistry, School of Dentistry, University of Minas Gerais (UFMG), Belo Horizonte, MG, Brazil

${ }^{3}$ Department of Operative Dentistry, School of Dentistry, Nove de Julho University (UNINOVE), São Paulo, SP, Brazil

\begin{abstract}
Aim: To evaluate the leakage on Er,Cr:YSGG laser- and bur- prepared Class V cavities restored with a silorane-based composite resin using different insertion techniques Methods: 40 cavities were outlined according to: the type of instrument [Er,Cr:YSGG laser (3.0 W power, energy per pulse of $150 \mathrm{~mJ}$, fluence of $53.57 \mathrm{~J} / \mathrm{cm}^{2}$, pulse duration of 140-200 $\mu \mathrm{s}, 20 \mathrm{~Hz}$ repetition rate and $55 / 65 \%$ air/water spray) or diamond bur]; and the type of filling technique (bulk increment or incremental). Four experimental groups were obtained ( $n=10)$ : $G 1$ - diamond bur (DB) and incremental (I); G2- DB and bulk increment (BI); G3- Er,Cr:YSGG and I; and G4- Er,Cr:YSGG and BI. Specimens were restored with a silorane-based composite resin (Filtek P90, 3M/ESPE), subjected to 500 thermal cycles, sealed, infiltrated with $2 \%(\mathrm{w} / \mathrm{v})$ methylene blue and sectioned in halves. Specimen analysis was scored based on a scale. Statistical analyses were done using the Kruskal-Wallis and Student Newman-Keuls tests $(\alpha=0.05)$. Results: Statistically significant differences were observed between $G 2$ and $G 4(p=0.003)$ and between $G 1$ and $G 2(p=0.028)$. The filling technique did not influence the pattern of dye leakage in the cavity walls $(p=0.151)$. Conclusions: Less leakage was observed when Er,Cr:YSGG cavities were restored with silorane-based composite resin, using the bulk increment technique. Nevertheless, cavities done using diamond bur have less leakage only when incrementally restored.
\end{abstract}

Keywords: dental leakage, lasers, polymerization, composite resins, tooth preparation.

Received for publication: March 23, 2013 Accepted: June 25, 2013

Correspondence to: Adriana Bona Matos

Av. Prof. Lineu Prestes, 2227, CEP: 05508-900

São Paulo, SP, Brasil

Phone: +55 1130917839 - ext 224

Fax: +551130917839

E-mail: bona@usp.br

\section{Introduction}

Dentistry has become more conservative, using minimally invasive techniques allied with new technologies ${ }^{1}$. Among several alternatives for preparation of conservative cavities, the use of Er,Cr:YSGG (Erbium, chromium:yttrium-scandiumgallium-garnet) laser has been proposed due to its high absorption of water and hydroxyapatite ${ }^{2}$.

Er,Cr:YSGG laser, when safely used in conjunction with air/water spray ${ }^{3}$ and 
appropriate irradiation parameters, have some advantages over conventional cavity preparation techniques, namely production of less noise and vibration, preservation of more tooth structure and less injury to pulp tissue, antibacterial properties, and no need of anesthesia during preparation ${ }^{4-5}$. Together, these advantages have led to an increased use of Er,Cr:YSGG laser in clinical practice, especially for patients who are anxious about pain and discomfort ${ }^{6}$.

Er,Cr:YSGG laser irradiation does not generate a smear layer ${ }^{7-9}$. Thus, the tooth surface presents exposed tubule apertures $^{8-9}$ with characteristics that suggest greater permeability of the irradiated surface. Reports are still controversial regarding the microleakage and bonding of resin monomers to irradiated dentin. While some authors ${ }^{10-13}$ suggest improved adhesion and less microleakage on irradiated surfaces, when compared with diamond burs, others show that microleakage is lower in irradiated dentin ${ }^{14}$. There is yet a third group of authors who claim no difference in adhesion to surfaces prepared with either laser irradiation or rotary instruments ${ }^{15}$. More information is needed to resolve the debate regarding irradiated dentin and resin monomer interaction and its ability to bond to tooth structure.

This discussion is even more important when new materials are introduced in the dental market. Silorane-based composite resins associated with its specific adhesive system are widely available for clinical application. These restorative systems, whose matrix is composed of organic silorane, claim to have lower polymerization shrinkage. This is a result of the silorane chemical reaction, which occurs through a cationic benzene ring-opening, promoting reduced resin shrinkage, when compared with methacrylate-based resins ${ }^{16}$. By reducing resin shrinkage, the clinical durability of restorations is increased as a result of good marginal sealing. According to the manufacturer instructions, this composite allows use of larger increments $(2 \mathrm{~mm})$, if inserted horizontally into the cavity. Thus, the chair-side time is reduced, which is highly desirable for shortening the treatment time. However, some authors still claim that the layering technique remains recommended even for low-shrinking materials ${ }^{17}$. It is fundamental to point out that these studies have been performed over conventionally prepared dentin, using diamond or carbide burs.

To our knowledge, there are currently no studies on the use of silorane-based composites and Er,Cr:YSGG laser-irradiated dentin. Therefore it might be expected that the different superficial dentin morphology originated by burs and lasers would influence leakage when silorane-based composite is used. The aim of this study was to compare the effects of the Er,Cr:YSGG laser cavity preparation technique with conventional preparation instruments, such as, diamond bur ${ }^{18-20}$ on the marginal leakage of silorane-based composite restorations. Moreover, the effects on leakage of the restorative technique used to insert the composite resin into the cavity was also evaluated.

\section{Material and methods}

The factors under study were cavity preparation method (Er,Cr:YSGG laser and diamond bur) and restorative technique (bulk Increment and incremental). The experimental units consisted of 40 cavities on erupted human third molars, randomly divided in 4 groups $(n=10)$. Leakage was assessed qualitatively.

\section{Tooth Selection}

After the approval of the research project by the institutional Ethics Committee (Protocol 108/10), 20 freshly extracted, erupted human third molars obtained by donation of the patients were collected and stored in distilled water at $4{ }^{\circ} \mathrm{C}$. Teeth were analyzed using a stereoscopic magnifying glass (Olympus, Hongo, Tokyo, Japan) at $25 \times$ magnification to selected only those without cracks or restorations.

\section{Cavity Preparation Procedures}

The dimensions of the standardized cavities on both buccal and lingual/palatal surfaces were $2.0 \mathrm{~mm}$ occlusogingival, $4.0 \mathrm{~mm}$ mesiodistal and $2.0 \mathrm{~mm}$ depth. Cavity outline was standardized using a template and its depth was guided by a periodontal probe. Cavities were made in the buccal and lingual/palatal surface of each tooth ${ }^{18-19}$, resulting in 40 cavities that divided into 4 groups $(n=10)$, according to method of cavity preparation and restorative technique. All cavities were prepared at the cervical third of the teeth, but all margins were located in enamel to produce a better marginal sealing. In groups G1 and G2 cavities were prepared with a \#1090 cylindrical diamond bur (KG Sorensen, Barueri, SP, Brazil) at high speed under constant water spray coolant ${ }^{20-}$ ${ }^{21}$. In groups G3 and G4, cavities were prepared with a Er,Cr:YSGG laser (Millennium, Biolase, San Clemente, CA, USA) belonging to the Biophotonics Laboratory of the Nuclear and Energy Research Institute; São Paulo, SP, Brazil; FAPESP-98/14270-8 CEPID Project). This laser has a 2.78 $\mu \mathrm{m}$ wavelength with pulse duration of 140-200 $\mu \mathrm{s}$. A sapphire fiber, model "G," with $600 \mathrm{~nm}$ in diameter and $4 \mathrm{~mm}$ in length, was attached to a \#2415 handpiece (Millennium, Biolase), which virtually touches the tooth. Irradiation parameters used for these groups were $3.0 \mathrm{~W}$ power, energy per pulse of $150 \mathrm{~mJ}$, fluence of $53,57 \mathrm{~J} / \mathrm{cm}^{2}, 150 \mathrm{~mJ}$ energy

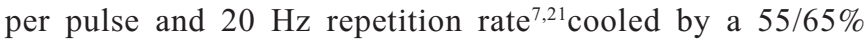
air/water spray. For a precise tissue irradiation control, an automatic pitch shifter XYZ micrometer (Model ESP 300 Newport Corporation, CA, USA) was used in such a way that the specimens were displaced during irradiation with standardized speed $(6.0 \mathrm{~mm} / \mathrm{s})$ and distances $(200 \mu \mathrm{m})$ between the pulses, avoiding any gaps between the laser pulses ${ }^{22}$.

\section{Restorative Technique}

Cavities were restored using a silorane-based composite resin (Filtek P90, 3M/ESPE, St. Paul, MN, USA) associated with Filtek P90 self-etch bonding agent. Following the manufacturer's instructions, primer solution was actively applied for $15 \mathrm{~s}$ and light-cured for $10 \mathrm{~s}$. The adhesive resin was then applied to all cavity walls and light-cured for $10 \mathrm{~s}$.

After applying the adhesive system, composite resin was inserted using different restorative techniques: incremental (G1 and G3) or bulk increment (G2 and G4). Groups filled 
with the incremental technique had composites inserted in approximately two horizontally oriented increments, each one light-cured for $40 \mathrm{~s}^{23-24}$, using a JetLite 4000 halogen lamp curing unit (J. Morita, Irvine, CA, USA), at a $1000 \mathrm{~mW} / \mathrm{cm}^{2}$ intensity. For groups treated with bulk increment, the composite resin was inserted at once, covering the cavity along the entire length and depth and polymerized for $40 \mathrm{~s}^{25-26}$.

\section{Finishing and Polishing of Restorations}

After the restorative procedure, specimens were stored in distilled water at $37^{\circ} \mathrm{C}$ for $24 \mathrm{~h}$. At the end of this period, finishing and polishing procedures were performed with silicone $\operatorname{tips}^{27-28}$ (Kit Enhance; Caulk Dentsply, Milford, DE, USA) at low speed (Kavo Brazil, Joinville, SC, Brazil). Restorations were polished until regular and smooth surfaces were obtained with well-defined borders and no excess material. Marginal adaptation was evaluated using a stereomicroscope at $40 \times$ magnification. The specimens were then stored in distilled water at $37^{\circ} \mathrm{C}$ for additional $24 \mathrm{~h}$.

\section{Thermal Aging Test}

Specimens were subjected to 500 thermal cycles $^{23-24}$, alternating baths between $5^{\circ} \mathrm{C}$ and $55^{\circ} \mathrm{C}$ for $1 \mathrm{~min}$ at each temperature, and $3 \mathrm{~s}$ of transfer time between baths.

\section{Leakage Test}

After thermal cycling, the specimens were sealed with two coats of nail polish (Risqué, São Paulo, SP, Brazil) up to $1 \mathrm{~mm}$ from the edge of the restoration. For the leakage test, specimens were then immersed in a $2 \%(\mathrm{w} / \mathrm{v})$ methylene blue solution (Merck, Darmstadt, Germany) ${ }^{29}$ for $4 \mathrm{~h}$ at $37^{\circ} \mathrm{C}$, followed by rinsing under running water for $15 \mathrm{~min}$ to eliminate the dye from the specimen surface.

\section{Leakage Evaluation}

Specimens were vertically sectioned in a buccolingual direction, through the center of the restoration. All halves were observed at $40 \times$ magnification (Miview USB Digital Microscope Video Camera, Cosview Technologies Co., Ltd, Longgang District, Shenzhen, China) and the half with a larger amount of dye was chosen to represent the specimen.

The specimens were scored according to the following criteria: $0=$ no dye penetration (Figure 1); 1 = partial dye penetration along the occlusal or gingival wall (Figure 2); 2 $=$ dye penetration along the occlusal or gingival wall but not including the axial wall (Figure 3 ); $3=$ dye penetration to and along the axial wall (Figure 4$)^{30}$.

The dye penetration was assessed by three independent calibrated examiners using a light microscope under $40 \times$ magnification. Cohen's kappa for inter-and intraexaminer reproducibility was 0.90 and 0.95 , respectively.

Data were analyzed with the program Bioestat 5.0 (Institute for Sustainable Development Mamirauá, Belém, AM, Brazil) and submitted to the nonparametric Kruskal-Wallis test followed by group comparison with Student-NewmanKeuls test $(\alpha=0.05)$.

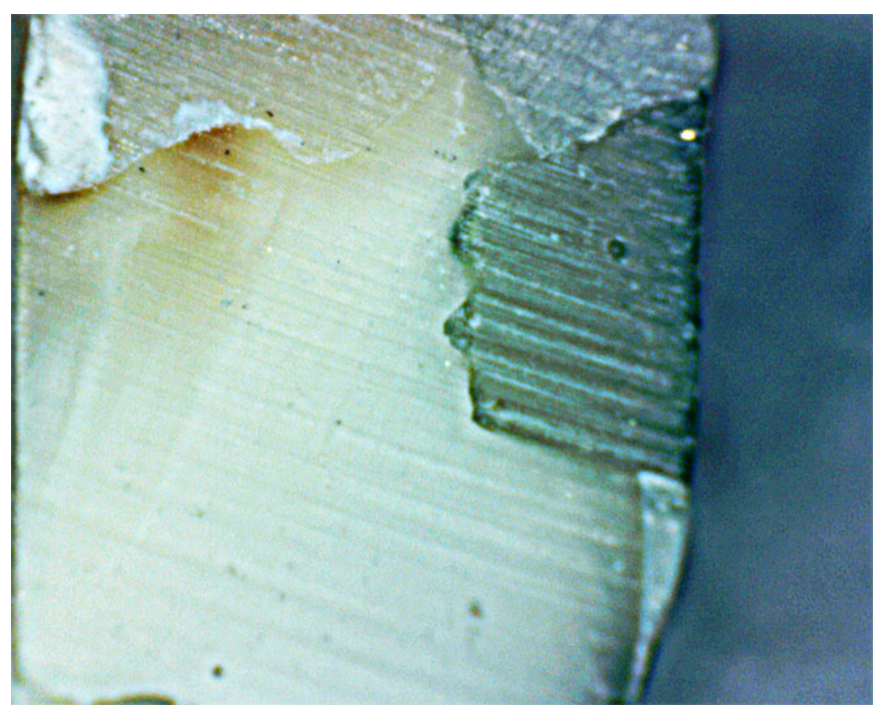

Fig. 1 - Image representative of score 0 (no dye penetration).

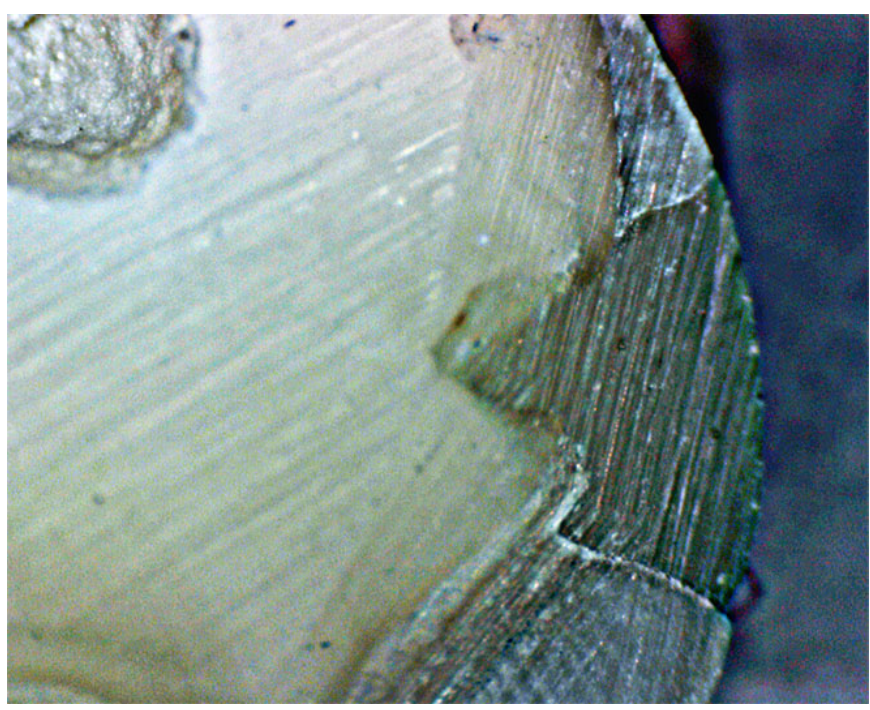

Fig. 2 - Image representative of score 1 (partial dye penetration along the occlusal or gingival wall).

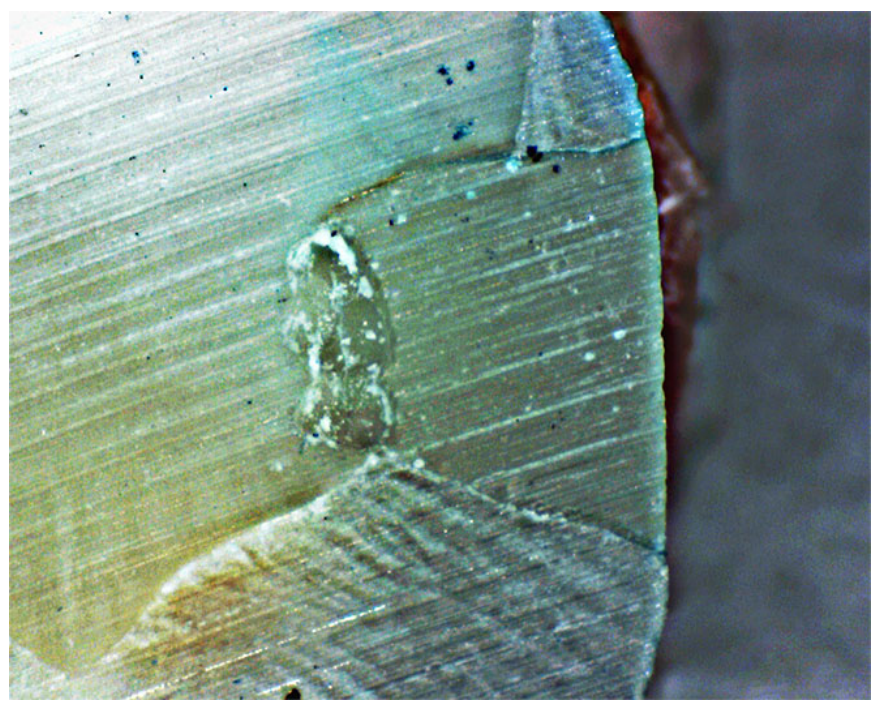

Fig. 3 - Image representative of score 2 (dye penetration along the occlusal or gingival wall but not including the axial wall). 


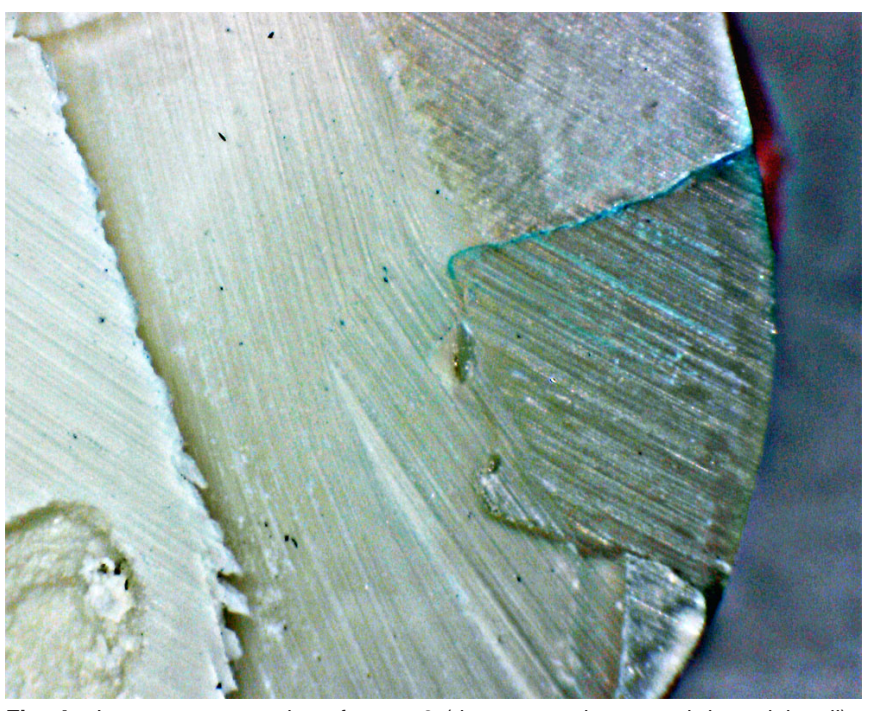

Fig. 4 - Image representative of score 3 (dye penetration to and the axial wall).

\section{Results}

The frequency distribution of dye penetration scores for the groups are presented in Table 1. The Kruskal Wallis test indicated that there is a significant difference between the tested groups $(p=0.013)$.

In groups restored with a bulk increment, Er,Cr:YSGG laser cavity preparation (G4) showed significantly less leakage than conventional preparation with diamond bur (G2) $(p=0.003)$. As for the incremental technique, there was no statistically significant difference between G1 (diamond bur) and G3 (Er,Cr:YSGG laser) $(\mathrm{p}=0.515)$.

When cavities were prepared with diamond bur (G1 x $\mathrm{G} 2$ ), there was less leakage when the restoration was done using the incremental technique $(\mathrm{p}=0.028)$. However, when cavities were prepared with Er,Cr:YSGG laser, the filling technique did not influence the pattern of dye leakage in the cavity walls $(p=0.151)$. The mean leakage score of experimental groups can be increasingly arranged (Table 2).

Table 1. Frequency distribution of dye penetration scores for each group

\begin{tabular}{lcccc}
\hline Group & Score 0 & Score 1 & Score 2 & Score 3 \\
G1 & 3 & 3 & 1 & 3 \\
G2 & 1 & 0 & 0 & 9 \\
G3 & 2 & 2 & 2 & 4 \\
G4 & 3 & 6 & 0 & 1 \\
\hline
\end{tabular}

Table 2. Median microleakage score in each group

\begin{tabular}{lllll}
\hline Groups $(\mathrm{n}=\mathbf{1 0})$ & $\mathbf{G 1}$ & G2 & G3 & G4 \\
Median & 1.78 & 2.93 & 2.12 & 1.37 \\
\hline
\end{tabular}

\section{Discussion}

This study evaluates leakage of silorane-based composite inserted using the bulk increment and incremental technique in cavities prepared with either Er,Cr:YSGG laser or diamond burs. The obtained results show that restoration of cavities made with Er,Cr:YSGG was beneficial with respect to the marginal sealing when the bulk increment technique was used. It could be attributed to the presence of silorane in the composite resin matrix. This restorative system consists of a silorane radiopaque low shrinkage base and a hydrophobic matrix, yielding lower polymerization shrinkage and reduced water absorption ${ }^{23,31}$.

During the silorane benzene ring break, polymer volume is only slightly lower than the non-cured $\operatorname{resin}^{16,23}$. This polymer also presents a low tension of polymerization, which is determined by the following factors: polymerization shrinkage, internal flow of material, polymerization kinetics, and polymerization rate ${ }^{16}$. Because the laser produces cavity walls with invaginations, the final surface area is larger, if compared with conventional methods of preparation. This reduces the tension associated with polymerization and the formation of marginal gaps, which in turn leads to less leakage than that observed when conventional methods are applied ${ }^{17}$. Moreover, the adhesive system used in conjunction with the silorane-based composite resin was specially developed for this type of resin, which optimizes filling due to its structural viscosity.

An important advantage of this silorane-based resin is the possibility of using larger increments, thereby reducing errors during the restorative procedure. According to the results of this study, Er,Cr:YSGG laser (G3 and G4) showed similar results of leakage irrespective of the restorative technique used. It is fundamental to point out that the best leakage performance was observed in Er,Cr:YSGG laser preparations restored with a bulk increment. Paradoxically, when cavities were prepared with diamond bur (G1 and G2), the use of the incremental filling technique showed less leakage when compared with bulk resin insertion, keeping the use of incremental technique for resin insertion fundamental, when cavities are conventionally prepared ${ }^{16,23}$.

It should be highlighted that due to the different composition and low polymerization shrinkage of the silorane-based composite resin, the manufacturer claims that this type of material can be used in layers up to $2 \mathrm{~mm}$, which means that the incremental composite insertion technique would be unnecessary for shallow cavities. This study confirmed this manufacturer's recommendation only when cavities were prepared with Er,Cr:YSGG laser, indicating that incremental insertion is still necessary for bur-prepared cavities, even though using a silorane-based resin ${ }^{32-33}$.

Several reports have evaluated microleakage of cavities made with erbium lasers ${ }^{11-13,15}$ and in some cases, the laser appears to be a detrimental factor, since it does not always form an appropriate hybrid layer, which leads to adhesive failure ${ }^{4,9,11}$. Authors claim that irradiation keep calcium attached to peritubular dentin, impairing the penetration of the adhesive systems and its proper hybrid layer formation ${ }^{3,5-}$ ${ }^{11}$. This is the first experiment that tested the association of silorane-based resins in laser prepared cavities.

Although other studies using additional methodologies are still needed to confirm the optimal performance of this 
resin in cavities made with lasers, our leakage results for silorane-based composite resin inserted in cavities prepared with $\mathrm{Er}, \mathrm{Cr}$ :YSGG laser are very promising ${ }^{2}$. The little leakage observed in Er,Cr:YSGG laser preparation indicates that Filtek P90 self-etch bonding agent adequately interacts with irradiated dentin and thus may be the adhesive that authors have been looking for since this laser was introduced in restorative dentistry for cavity preparation.

It may be concluded that silorane-based composite resin bulk increment restorations presented less leakage when cavities were made with Er,Cr:YSGG laser. Conversely, for cavities prepared with diamond bur, the use of the incremental technique seems to be necessary to produce less leakage at the restoration interface.

\section{Acknowledgments}

The authors would like to thank IPEN for allowing use of the Er,Cr:YSGG laser.

\section{References}

1. Ergucu Z, Celik EU, Unlu N, Turkun M, Ozer F. Effect of Er,Cr: YSGG laser on the microtensile bond strength of two different adhesives to the sound and caries-affected dentin. Oper Dent. 2009; 34: 460-6.

2. Ramos TM, Ramos-Oliveira TM, Moretto SG, de Freitas PM, EstevesOliveira M, de Paula Eduardo C. Microtensile bond strength analysis of adhesive systems to Er: YAG and Er,Cr: YSGG laser-treated dentin. Lasers Med Sci. 2013 Jan 26; DOI 10.1007/s10103-012-1261-6.

3. Kilinc E, Roshkind DM, Antonson SA, Antonson DE, Hardigan PC, Siegel SC, et al. Thermal safety of Er: YAG and Er,Cr: YSGG lasers in hard tissue removal. Photomed Laser Surg. 2009; 27: 565-70.

4. Cehreli SB, Gungor HC, Karabulut E. Er,Cr: YSGG laser pretreatment of primary teeth for bonded fissure sealant application: a quantitative microleakage study. J Adhes Dent. 2006; 8: 381-6.

5. de Oliveira MT, de Freitas PM, de Paula Eduardo C, Ambrosano GM, Giannini M. Influence of Diamond Sono-Abrasion, Air-Abrasion and Er: YAG Laser Irradiation on Bonding of Different Adhesive Systems to Dentin. Eur J Dent. 2007; 1: 158-66.

6. Keller U, Hibst R, Geurtsen W, Schilke R, Heidemann D, Klaiber B, et al. Erbium: YAG laser application in caries therapy. Evaluation of patient perception and acceptance. J Dent. 1998; 26: 649-56.

7. Yu DG, Kimura Y, Kinoshita J, Matsumoto K. Morphological and atomic analytical studies on enamel and dentin irradiated by an erbium, chromium: YSGG laser. J Clin Laser Med Surg. 2000; 18: 139-43.

8. Moretto SG, Azambuja Jr N, Arana-Chavez VE, Reis AF, Giannini M, Eduardo Cde $\mathrm{P}$, et al. Effects of ultramorphological changes on adhesion to lased dentin-Scanning electron microscopy and transmission electron microscopy analysis. Microsc Res Tec. 2011; 74: 720-6.

9. Aranha AC, De Paula Eduardo C, Gutknecht N, Marques MM, Ramalho $\mathrm{KM}$, Apel C. Analysis of the interfacial micromorphology of adhesive systems in cavities prepared with Er,Cr: YSGG, Er: YAG laser and bur. Microsc Res Tec. 2007; 70: 745-51.

10. Moldes VL, Capp Cl, Navarro RS, Matos AB, Youssef MN, Cassoni A. In vitro microleakage of composite restorations prepared by Er: YAG/ $\mathrm{Er}, \mathrm{Cr}$ : YSGG lasers and conventional drills associated with two adhesive systems. J Adhes Dent. 2009; 11: 221-9.

11. Esteves-Oliveira M, Zezell DM, Apel C, Turbino ML, Aranha AC, Eduardo Cde P, et al. Bond strength of self-etching primer to bur cut, Er,Cr: YSGG, and Er: YAG lased dental surfaces. Photomed Laser Surg. 2007; 25: 373-80.
12. Shahabi S, Ebrahimpour L, Walsh LJ. Microleakage of composite resin restorations in cervical cavities prepared by Er,Cr: YSGG laser radiation. Aust Dent J. 2008; 53: 172-5.

13. Palma Dibb RG, Milori Corona SA, Borsatto MC, Ferreira KC, Pereira Ramos R, Djalma Pecora J. Assessing microleakage on class V composite resin restorations after Er: YAG laser preparation varying the adhesive systems. J Clin Laser Med Surg. 2002; 20: 129-33.

14. Hossain M, Nakamura $Y$, Yamada $Y$, Kimura $Y$, Matsumoto N, Matsumoto K. Effects of Er,Cr: YSGG laser irradiation in human enamel and dentin: ablation and morphological studies. J Clin Laser Med Surg. 1999; 17: 155-9.

15. Ergucu Z, Celik EU, Turkun M. Microleakage study of different adhesive systems in Class V cavities prepared by Er,Cr: YSGG laser and bur preparation. Gen Dent. 2007; 55: 27-32.

16. Weinmann W, Thalacker $C$, Guggenberger R. Siloranes in dental composites. Dent Mater. 2005; 21: 68-74.

17. Ilie N, Hickel R. Silorane-based dental composite: behavior and abilities. Dent Mater J. 2006; 25: 445-54.

18. Karaarslan ES, Usumez A, Ozturk B, Cebe MA. Effect of cavity preparation techniques and different preheating procedures on microleakage of class $V$ resin restorations. Eur J Dent. 2012; 6: 87-94.

19. Yaman BC, Guray BE, Dorter C, Gomec Y, Yazicioglu O, Erdilek D. Effect of the erbium: yttrium-aluminum-garnet laser or diamond bur cavity preparation on the marginal microleakage of class $\mathrm{V}$ cavities restored with different adhesives and composite systems. Lasers Med Sci. 2012; 27: 785-94.

20. Oskoee PA, Kimyai S, Ebrahimi Chaharom ME, Rikhtegaran S, PournaghiAzar F. Cervical margin integrity of Class II resin composite restorations in laser- and bur-prepared cavities using three different adhesive systems. Oper Dent. 2012; 37: 316-23.

21. Lee BS, Lin PY, Chen MH, Hsieh TT, Lin CP, Lai JY, et al. Tensile bond strength of Er,Cr: YSGG laser-irradiated human dentin and analysis of dentin-resin interface. Dent Mater. 2007; 23: 570-8.

22. Aranha AC, Pimenta LA. Effect of two different restorative techniques using resin-based composites on microleakage. Am J Dent. 2004; 17: 99-103.

23. Monteiro GQ, Montes MA, Gomes AS, Mota CC, Campello SL, Freitas AZ. Marginal analysis of resin composite restorative systems using optical coherence tomography. Dent Mater. 2011; 27: e213-23.

24. Yazici AR, Yildirim Z, Antonson SA, Kilinc E, Koch D, Antonson DE, et al. Comparison of the Er,Cr: YSGG laser with a chemical vapour deposition bur and conventional techniques for cavity preparation: a microleakage study. Lasers Med Sci. 2012; 27: 23-9.

25. Wei YJ, Silikas N, Zhang ZT, Watts DC. Hygroscopic dimensional changes of self-adhering and new resin-matrix composites during water sorption/ desorption cycles. Dent Mater. 2011; 27: 259-66.

26. Calheiros FC, Sadek FT, Braga RR, Cardoso PE. Polymerization contraction stress of low-shrinkage composites and its correlation with microleakage in class $V$ restorations. J Dent. 2004; 32: 407-12.

27. Antonson SA, Yazici AR, Kilinc E, Antonson DE, Hardigan PC. Comparison of different finishing/polishing systems on surface roughness and gloss of resin composites. J Dent. 2011; 39(Suppl 1): e9-17.

28. Berger SB, Palialol AR, Cavalli V, Giannini M. Surface roughness and staining susceptibility of composite resins after finishing and polishing. $J$ Esthet Restor Dent. 2011; 23: 34-43.

29. Antonson SA, Yazici AR, Okte Z, Villalta P, Antonson DE, Hardigan PC. Effect of resealing on microleakage of resin composite restorations in relationship to margin design and composite type. Eur J Dent. 2012; 6: 389-95.

30. Arslan S, Yazici AR, Gorucu J, Pala K, Antonson DE, Antonson SA, et al. Comparison of the effects of Er,Cr: YSGG laser and different cavity disinfection agents on microleakage of current adhesives. Lasers Med Sci. 2012; 27: 805-11.

31. Baracco B, Perdigao J, Cabrera E, Giraldez I, Ceballos L. Clinical evaluation of a low-shrinkage composite in posterior restorations: one-year results. Oper Dent. 2012; 37: 117-29. 
32. Poureslami HR, Sajadi F, Sharifi M, Farzin Ebrahimi S. Marginal Microleakage of Low-shrinkage Composite Silorane in Primary Teeth: An In Vitro Study. J Dent Res Dent Clin Dent Prospects. 2012; 6: 94-7.

33. Schmidt M, Kirkevang LL, Horsted-Bindslev P, Poulsen S. Marginal adaptation of a low-shrinkage silorane-based composite: 1-year randomized clinical trial. Clin Oral Investig. 2011; 15: 291-5. 